\title{
Looking Thru the Nano Lens: Art, Science and Nature
}

\author{
Chiara O’Reilly $^{\mathrm{a}}$, Alice Motion ${ }^{\mathrm{bc}}$, Chiara Neto $^{\mathrm{bc}}$ \\ Corresponding author: Chiara O’Reilly (chiara.oreilly@sydney.edu.au) \\ a Department of Art History, University of Sydney \\ ${ }^{\mathrm{b}}$ School of Chemistry, University of Sydney \\ ${ }^{c}$ The University of Sydney Nano Institute, University of Sydney
}

Keywords: nano, science, art, public engagement, collaboration

\begin{abstract}
In 2018, an interdisciplinary team of researchers from the School of Chemistry, Sydney Nano and the Department of Art History at the University of Sydney set up a pilot project called the Nano Lens. Our project set out to examine and experiment with what it means to look closely at the natural world and inviting us, as colleagues, into a discussion and collaboration, drawing on our different perspectives. The Nano Lens also gave agency to a group of scientists in training (undergraduate and postgraduate students), and a sense of ownership of the science, which was then transmitted to the public. Taking inspiration from the artwork of the prominent Australian painter Margaret Preston (1875-1963) and the flora she depicted, the Nano Lens has opened up new research that intersects science and the arts; celebrating the value of collaboration and offering opportunities for staff and students to engage in and lead interdisciplinary discussions with the public. This paper will discuss our pilot project and the initial findings of our research together and discuss the benefits that our alliance has had in fostering collaboration and outreach activities where academics and students work together to share their research with the public. We seek to reflect on what we have learnt from the project and from opportunities to share our work and approaches. What does it mean to look like a scientist or to look like an artist and how has this enriched student learning? What value is there in opening up opportunities for informal learning about science and collaboration outside your disciplines?
\end{abstract}

\section{Introduction}

Late in 2017, a call was made for pilot projects at the University of Sydney to develop collaborative research between the Faculty of Arts and Social Sciences and the Sydney Nano Institute, around the theme of 'Human Perspectives on the Nano Scale'. The call required a short video pitch, and then a second round of selection, where applicants were invited to pitch their ideas directly to an audience of Sydney Nano Staff. Standing in front of this audience, each team presented their idea and responded to questions and provocations from the floor. Chiara O'Reilly pitched the Nano Lens; describing it as a 'project all about looking' and one that would 'explore the ideas of what looking means across art and science.' O'Reilly wanted to use the pilot project to challenge the notion of what is familiar within visual experience and examine this all the way down to the nanoscale; an opportunity to bring back an almost childlike sense of wonder and excitement in the world around us. By combining art, nature and nanoscience the project aimed to make nanoscience more accessible and relatable to a wider audience. The Nano Lens project quickly drew a dedicated team - Chiara Neto, Alice Motion and Chiara O'Reilly - each embracing the opportunity to work together and share in a collaborative research process. 


\section{Building an interdisciplinary team}

The most satisfying aspect of our project to date is our ability to bring diverse expertise and knowledge and then collaborate with a strong sense of partnership and creativity. Chiara Neto is a physical chemist, interested in the wetting properties and microstructure of surfaces, including those of natural surfaces; Alice Motion's research focuses on open source drug discovery and exploring ways to connect science with the public through science communication, outreach, participation and education; and while Chiara O'Reilly trained as an art historian, her recent research is into Museums and how they present their collections and engage with the public.

From our initial discussions we have developed the Nano Lens to serve a series of different purposes and audiences. It has allowed us to engage in scientific and humanities-driven research; we have worked with undergraduate and higher degree research students; we have developed educational resources for use in higher education, K-12 education and for a general audience seeking to engage in life-long learning (for details on the project, see: thenanolens.com). The project has so far been presented to two internal and five external audiences. Across 2018, these groups included research presentations at the University of Sydney, a workshop at the Australian Science Teachers Association CONASTA 67 ( 30 teachers), a 'Making and Doing' session as part of the Society for Social Studies of Science Conference: 4S Sydney, and a paper at the Australian Science Communicators 10th National Conference. Alongside our dissemination in academic settings, we launched the event to the public as part of the Royal Botanic Gardens (RBG) Living Laboratory for National Science Week in 2018 (attendance 2500) and ran workshops for children at a local primary school ( 30 students, $\sim 10$ per workshop).

Core to the success of the project has been the opportunity to play to our strengths. Neto's focus on surfaces in the natural world has driven our concentration on nature and natural structures. Motion's expertise in citizen science and open access has offered a guiding philosophy to the work, while O'Reilly brought to the project her knowledge of art history and the collections and approaches of cultural institutions to the table.

To coalesce these diverse skills, we focused on the Australian artist Margaret Preston (18751963), because her still life paintings and prints are well known and celebrated for their use of Australian flora. There is an extensive scholarship into Preston's life and work as an artist, and the University of Sydney has several of her works in its art collection (Figure 1) (Butler, 1987; Edwards, Preston, Peel, \& Mimmocchi, 2005). Her paintings often represent plants which are endemic to the Sydney region, many of which grow locally which meant that we were able to select specimens that were in flower and possible to source. In many respects, Preston seemed to embody the spirit of our project as she declared in one of her frequently quoted aphorisms: 'Why there are so many tables of still life in modern paintings is because they are really laboratory tables on which aesthetic problems can be isolated' (Preston, 1929, np). Her description of the process of still life as comparable to the space of a laboratory highlights the act of representation and understanding, and was useful for us because it drew out a view of art and science as a shared intellectual exercise of active problem-solving. 


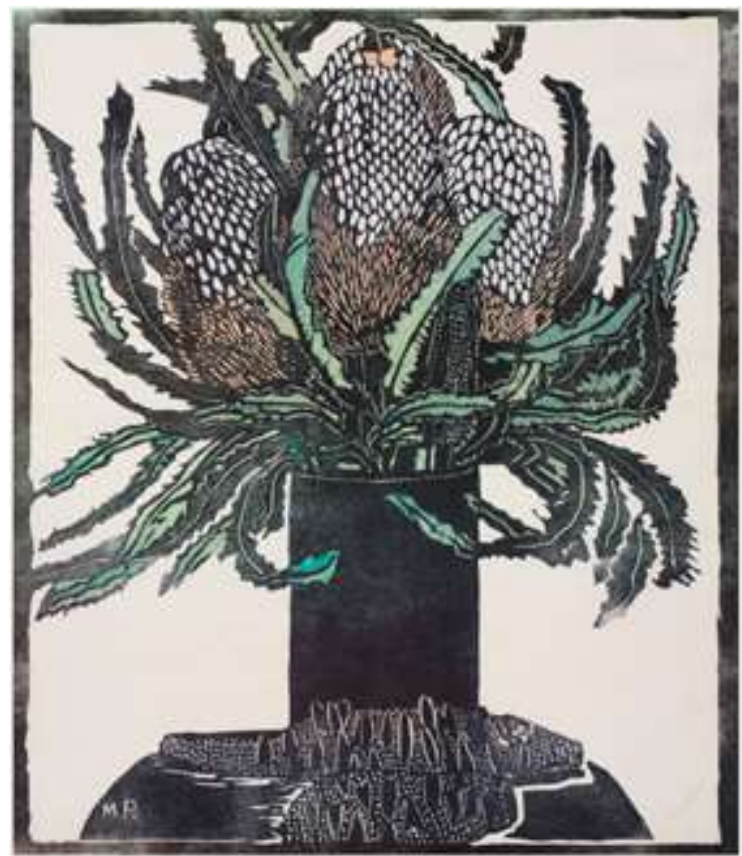

Figure 1: Margaret Preston (1875-1963), Western Australian Banksia, 1929, print, $45.4 \mathrm{x}$ $38.9 \mathrm{~cm}$, Donated through the Hon R P Meagher bequest 2011. University Art Collection, University of Sydney UA2012.316

(C) Margaret Preston/Copyright Agency, 2019.

Conceptually, nanoscience can feel intimidating to students and members of the public who are asked to imagine scales far smaller than the eye can see. The development of exercises that call for close looking at natural objects and the detection of macro properties that are indicative of nanostructures can help students to feel more comfortable in their exploration.

Working as a group we have developed the Nano Lens - a project which draws on our combined skills and has driven us to think about the intersections and possibilities in bringing art and science together and how they can operate better together.

\section{Personal perspectives}

In this paper, we will share our personal perspectives as scholars with differing disciplinary backgrounds and summarise the outcomes of our pilot project, the initial findings of our research together and the benefits that it has had in fostering collaboration and outreach activities where academics and students work together to share their research with the public. The new partnership was established not only among academic colleagues with different disciplinary backgrounds (art history, physical chemistry, science communication). The partnership also involved burgeoning scientists, namely undergraduate and postgraduate students, who demonstrated the outreach activities during National Science Week to the public. The demonstrators showed enthusiasm and competence while running the hands-on activities with the public, and managed to get the public to actively participate in the exploration of natural surfaces. The project gave the students agency and a sense of ownership of the science; feelings that were transmitted to the public. Exploring our research and practice through an ethnographic lens has enabled us to reflect on the impact of creative teaching practices for ourselves, our students and the broader community. 


\section{Looking thru art - Dr Chiara O'Reilly}

I typically work with Museum collections, art, cultural objects and museological theory to explore the intersections between collections and how the public experience them (Lawrenson and O'Reilly, 2018; O'Reilly, 2019). Central to my scholarly approach and interest is the notion of visual experience (See Arrase, 2013; Jay, 1994). I rely profoundly on my ability to take in information and details visually. Yet I have rarely had an opportunity to focus a project on the visual and consider the potential of new visual discovery.

The idea behind this study was a focus on vision and visual exploration, to link different ways of seeing, to link scientists with art historians and museum collections, to examine what we see and how we understand the world. Fundamental to my approach to the topic was an understanding that artists must understand nature to be able to represent it, and the centrality to this process of close study, their detailed observations and how they are brought together in the act of representation. Although there are traditions and conventions that shape the representation of nature, great artists invent a nature, so much so that we can look at a landscape and say it looks like a John Constable, or a cubist still life is still readable as a bowl of fruit Our language is littered with phrases that celebrate the visual: phrases like 'a good eye', a 'bird's eye view' or words like 'insight' all celebrate visual skill and competence and the core role it plays in comprehension of the world around us.

Some of the key aspects I was interested in exploring in this project related to the chance to return to curiosity and wonder, a chance to look at the world around us from a variety of different perspectives that would in effect make us see it anew (see the work of Alpers, 1983; Greenblatt, 1990) . Preston offered a subject who is familiar to many Australians, her works are frequently reproduced as posters and tea towels and thus often seen as decoration in houses or offices. Using her still life paintings as a base meant that there was a degree of familiarity, but, they also invited close study - to examine the details of the paintings, the way that she constructs and plays with her subject matter and to better understand how she had represented the flora. This process of close study is fundamental to art history, but the concentrated study of an artwork rarely happens in an Art Gallery, in fact most studies suggest we look at a painting for less than 10 seconds in a gallery (Carbon, 2017; Locher, 2015; Smith, Smith \& Tinio, 2017).

Thus I saw the project as an exercise in slow and close looking (Tishman, 2018). I focused on a small number of works by Preston, which represented flora we could obtain to examine, and began to explore when she painted them, the compositional differences she experimented with alongside the history of how the works came into their collections and the historical context of the objects themselves. This was a classical approach that combined Museological and Art Historical skill, building a rich understanding of Preston, her work and its reception.

Working with the Nano Lens team offered a new perspective and invited me to see Preston's compositions as well as the world around me anew. Scanning electron microscopy (SEM) images (Figure 2) offered a new perspective of the possibility of what a detail could be; no longer did detail in the natural world stop, in fact the images we assembled built a picture of continuous detail and structure - a visual drilling into the plant. 


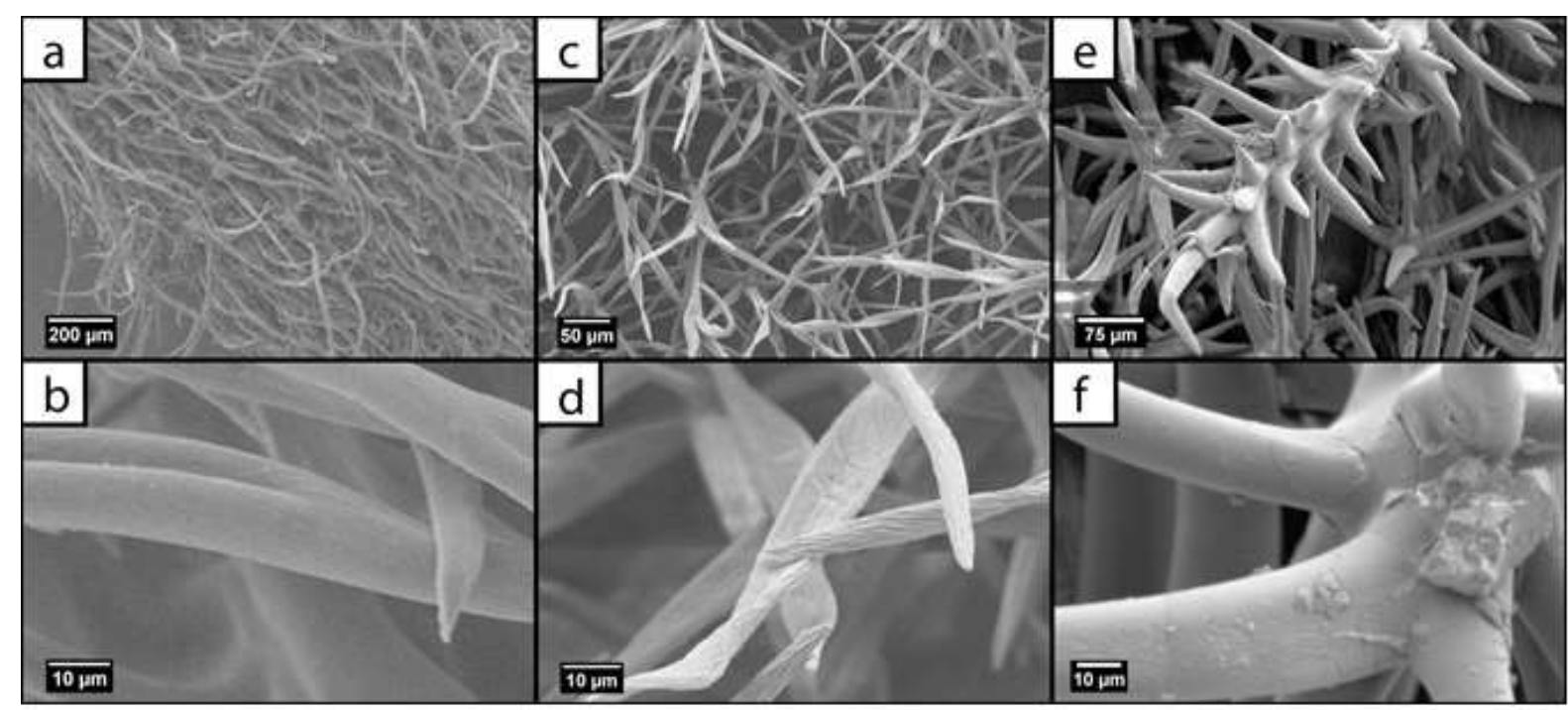

Figure 2: Scanning electron micrographs of the saw-tooth Banksia serrataflower (a, b), Actinotus helianthin Flower (flannel flower) (c, d), and Anigozanthos manglesii (kangaroo paw) (e,f). Taken by Anthony Katselas

The experience challenged me to look at the complexity of a Banksia flower in a fresh way. In nature my study, like an artist, had been limited to observing the intricacy in its visible structure. My photographs and amateur sketches gave me an opportunity to look at the details but failed to truly capture how they worked as a structure. Preston's work glides over the precise detail, unlike say a botanical artist's rendering, but in her process she arrives at a representation that is highly suggestive of the structure and solidity of these flowers, often transforming them into almost architectural forms that are balanced and expertly positioned in the composition. The SEM images reminded me how what we see in the natural world can be a beginning. The conversations we have had to date have challenged me to rethink ideas of observation, highlighting how human looking has been shaped over time by technology and how SEM and other instruments in effect open up a new visual spaces.

Through our collaboration my understanding and appreciation for Preston has been reinvigorated as I have a renewed appreciation for the complexities of still life and the challenges of representing what we see and how we understand the world around us. Linking her art with nanoscience has opened up new research for me and invited new potential to engage with this research and present it to diverse audiences and that has been an incredible opportunity.

\section{Looking thru science - Associate Professor Chiara Neto}

I am a physical chemist and my research focuses on the study of surfaces. My group's work often takes inspiration from natural surfaces, to achieve new materials that are energy efficient. Some of our research addresses challenges such as developing self-cleaning paints (Ware et al., 2018), coatings that decrease drag (Scarratt, Steiner, \& Neto, 2017; Scarratt, Zhu, \& Neto, 2019) and surfaces that collect water from the atmosphere (Al-Khayat, Hong, Beck, Minett, \& Neto, 2016).

The Nano Lens project appeals to me because I am fascinated by natural patterns and surfaces, their functionality and beauty, and how we can learn from nature to develop new functional materials. For example, one area of my research involves designing extremely water-repellent surfaces - so called superhydrophobic surfaces - that mimic a lotus leaf (Scarratt et al., 2017). A lotus leaf emerges from a muddy pond clean and dry, because water cannot wet the leaf, 
droplets roll off its surface, taking with them dust particles, and leaving no residuals behind. Such a self-cleaning effect derives from the combination of the hydrophobic (water-hating) coating of the leaf, and the special surface roughness (nanoscale and microscale) of the leaf, that is able to trap pockets of air within its structure.

The Nano Lens gave us the opportunity to focus (literally and figuratively) on the sophisticated structure of natural surfaces. We chose to stop and look closely at leaves and flowers that we usually observe only in passing in everyday life. In a surface science laboratory, we have the means to look closely: we can image surface features at the nanoscale (one thousand times smaller than the width of a hair) by using techniques such as scanning electron microscopy (SEM). We can then relate the structure to a function, e.g. how a surface interacts with liquids. For this, we measure the contact angle that a droplet of water forms when placed onto a surface (Figure 3), i.e. we quantify its shape. For example, on a superhydrophobic surface a water droplet has a high contact angle, above 150 degrees. We discovered that, after taking these kinds of observations, we were more likely to notice and appreciate details of flora even while taking a walk. Indeed, the Nano Lens has developed in us, and the students involved, a fascination with natural patterns and their visual representation.

\section{water droplet}

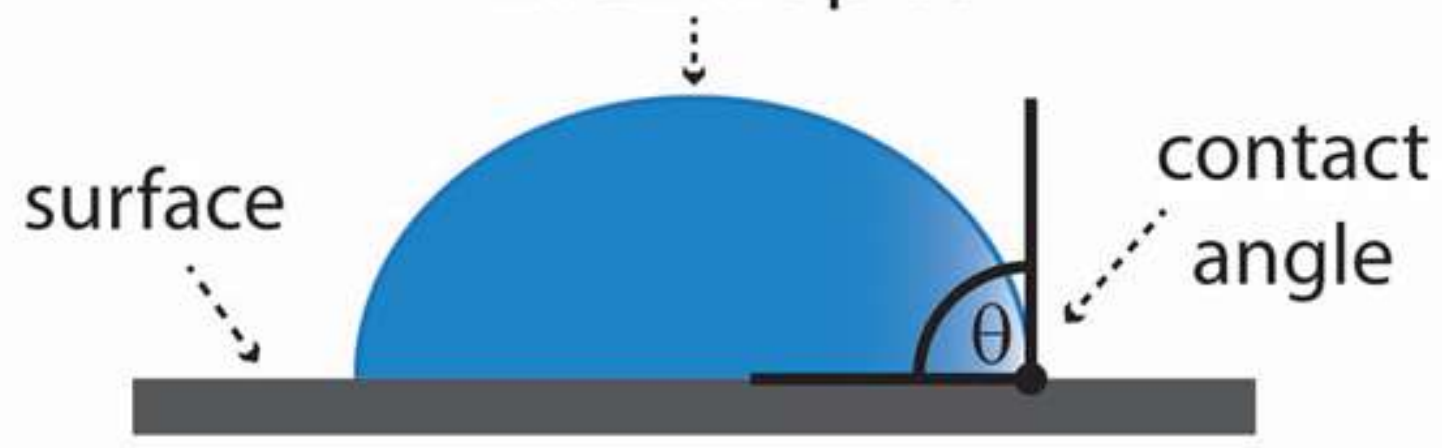

\section{Figure 3: Schematic showing contact angle of a droplet of water on a surface}

The experience of the Nano Lens has been extremely rewarding for me. Working with colleagues from other disciplines has encouraged me to ask research questions that I had not explored before. For example, we decided to look at the surface structure and wetting properties of native Australian plants, chosen based on the subjects of Preston's art. We were surprised to find that the surface of the leaves and flowers of these Australian natives were also superhydrophobic, to extents similar to a lotus leaf. We discovered on the surfaces of native plants intricate and sophisticated structures on the nano- and microscale. During the project, an undergraduate summer scholar trained in the use of SEM and contact angle measurements to conduct the experiments, learned to communicate in a multidisciplinary context, to work with open-ended questions and to develop laboratory experiments for undergraduates (Katselas, Motion, O'Reilly, \& Neto, 2019). The published work on the undergraduate laboratory experiments will give the skills and encourage agency to explore the microscale structure and properties of natural surfaces to many student groups across the globe. Through the Nano Lens I have enjoyed being able to share my research interests with a wider audience, and I have learned about how to engage with the public in a way that is rewarding.

\section{Opening up learning - Dr Alice Motion}

Though an organic chemist by training, my research focuses on opening up science through scholarship and practice in open source drug discovery (Williamson et al., 2016 and 
breakinggoodproject.com) and exploration of Science Communication, Outreach, Participation and Education (SCOPE). I instantly saw the appeal of working with Chiara O'Reilly and Chiara Neto as part of the Nano Lens Project and the rich possibilities of framing an arts and science collaboration through the common shared experience of 'looking'. As chemists, we are by definition 'natural scientists', but as scientists who explore the properties of matter and the way that it changes, we are often focused on the beauty that we 'see' at scales far too small for the human eye rather than the beauty of the macro; the natural world around us. Although public interest and engagement with science has increased since the late 1980s ('Trends in public attitudes to science | NCCPE', 2018), Science still remains inaccessible to many. There is a sense that while Art belongs to everyone, Science is somehow separate and not fully integrated as part of 'culture'. The visual appeal of Preston's paintings, and her popularity in Australia and beyond, provided an opportunity to capture the attention of students and citizens who may not otherwise be engaged by science. The invitation to 'look' closely at still life and then samples of native Australian flora at the macro level, provided an engaging and accessible entry into scientific concepts and ideas relating to the nanoscale.

My role, as part of this interdisciplinary team, has been to lead the development of formal and informal educational activities for different audiences and to encourage people to first look at the macro and then be inspired to zoom in to the micro or nanoscale.

Together with two undergraduate students (one on a summer scholarship), we worked to develop activities that would be suitable for school aged children and trialled them in a high school workshop as part of the Australian Science Teachers Association CONASTA 67 (National conference of the Australian Science Teachers Association, 2018). In the workshop, we trialled a method of measuring contact angle using inexpensive and readily available equipment, provided USB microscopes for participants to look closely at samples of native Australian flowers and to encourage the teachers to start to draw the specimens provided. It was interesting to see the hesitation of some science teachers to start drawing the flowers provided, perhaps an interesting parallel to the hesitation of some of their own students to engage in science experiments. The workshop feedback provided encouragement from high school science teachers and some interesting insight for further development of the project. The teachers saw value in connecting the disciplines of science, art and nature to provide a holistic project-based learning experience. Some commented that combining mixed methods of looking might help to engage students who felt more strongly connected to art or to science and provide a new 'way in' to STEM (science, technology, engineering and mathematics) or indeed art, whichever a given student finds more challenging.

As part of the Sydney Science Festival, we brought the Nano Lens project to the general public through an interactive open-air exhibit in the Royal Botanic Gardens (RBG, Figure 4). Postgraduate and undergraduate students were involved in illustrating the project to the public. During the one-day event, our team had hundreds of discussions about surface chemistry research, nanoscience and artistic interpretation. The 'looking like a scientist' part of the exhibit featured USB microscopes and computer screens so that members of the public could explore the detail in flowers and leaves provided by the RBG. 


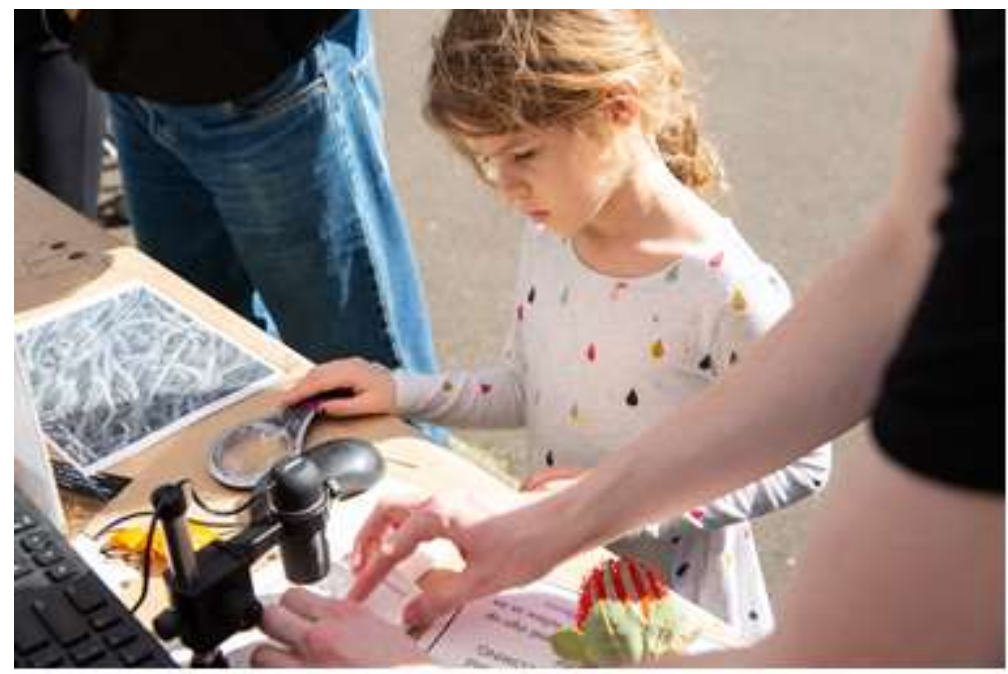

Figure 4: A young participant looking through a USB microscope to zoom in on the detail of some native Australian flora - Photograph by Katje Ford

Working with Chiara O'Reilly prior to the event, we carved patterns inspired by an SEM image of the Banksia leaf into sheets of rubber to make stamps for the public to use in the creation of a communal artwork in the 'looking like an artist' part of an exhibit (Figure 5). We drew the outline of Banksia leaves onto large sheets of paper and provided drawing materials, stamps and paper for use by the public. A series of printed images showed images of the Banksia leaf as magnified in the SEM, and guided the public to imagine the zoomed-in surface of the leaf. This inspired them to produce large Banksia shaped leaves decorated with colourful stamps echoing the exquisite structural elements revealed by looking very closely. An artist, Madeline Kelly (Kelly, 2018), sat with us on the day and drew flowers and plants alongside members of the public, encouraging them and offering advice to those who sought her input. Seeing young and old connect spending time with both the artistic and scientific aspects of our project simultaneously and swapping between activities was wonderful to observe, and a clear reminder of the ability of people to organically move between science and art, without necessarily confining each discipline to separate activities, lessons or events.

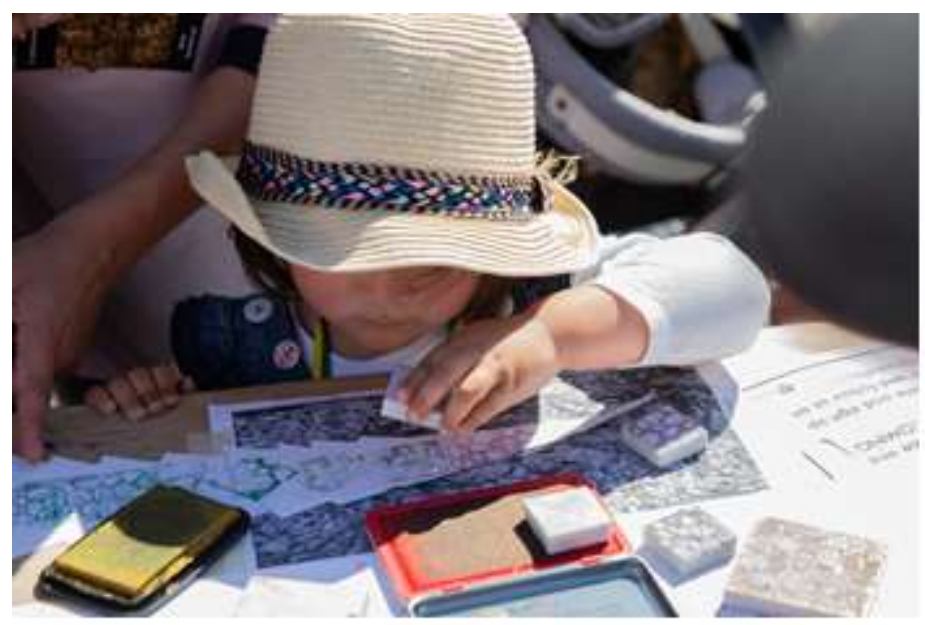

Figure 5: A young participant using rubber stamps to create communal Banksia leaf artwork - Photograph by Katje Ford 
Similar activities were applied in a K-12 setting in a Sydney primary school. Watching young children's amazement at magnified images of flowers and their ability to intuitively operate the microscopes was a wonderful experience. Their enthusiasm for dissection of the flowers and leaves; pulling them apart to explore the structures within were reminiscent of both the work of a scientist and Preston's own accounts in a 1945 radio interview of dissecting flowers and studying their details: "When I am painting flowers I'll pull one of its kind to pieces. I will know exactly how it's formed. When I've done this I draw from another one - I do this with all my flowers. I make studies of them."(Ure Smith, 1945). This is indeed the same process that scientists would undertake in botany classes. The slow process of understanding the flowers evident in Preston's comments was mimicked by the students who swapped between 'science' and 'art' activities where they drew flowers/plants or created printed collages of the zoomed in Banksia structures.

Recognising the educational potential of this project, I have continued to work with talented undergraduate students and honours students to develop an interdisciplinary undergraduate laboratory experiment and a citizen science platform to fully expand the Nano Lens project (Katselas et al., 2019).

Personally, the experience of collaborating with two established female researchers from a different chemistry background and a completely different faculty has inspired me to rethink the way in which I teach science and communicate chemistry. For example, while I have been a strong proponent of research-enhanced and problem-based learning and teaching, the Nano Lens project has given me the confidence to enter into lessons or discussions around the physical sciences that are first stimulated by looking at art or nature. It has been a transformative experience for my career and a privilege to explore science through creativity and play.

\section{Summary}

The Nano Lens has provided a unique opportunity for three scholars from different disciplines to work together and produce a rich and exciting program of research that is greater than the sum of its parts. While generating new research data on the physical properties of natural surfaces, and exploring the work of Preston, we have successfully piloted outreach, education and science communication projects that are primed to scale. We have taken this work into the curriculum by publishing articles that describe suitable undergraduate laboratory practicals, and opened up our research to a wider public through discussions in the Sydney Universities museums magazine Muse (Motion, Neto, \& O'Reilly, 2019). By combining the disciplines of Science and Arts, we have created multiple points of entry into engaging with the topic, and developed educational programs that enable participants to look at the natural world anew, inspired by our own experiences as researchers in the project.

We look forward to launching the Nano Lens citizen science project and disseminating other findings from our research together. Looking together as Artists and Scientists has enabled us to reflect on our own research and practice and has established an interdisciplinary research team, which includes both undergraduate and postgraduate students, as well as colleagues. We value and embody more holistic approaches to learning science, art and mathematics and model this to our students, to our colleagues and to the general public. 


\section{Acknowledgements}

The authors would like to acknowledge and thank SSSHARC and Sydney Nano for funding, Anthony Katselas a Denison Summer Student on this project who collected specimens and recorded SEM images, Dalyell Scholars, Talented Student Program students and volunteer students who worked on the development of the citizen science project, Christina McGhee and Sophie Daniel from the Royal Botanic Garden and organisers of the Living Laboratory event for National Science Week, Teachers at the CONASTA workshop, students of local primary schools and Manon, Emile, Dante and Matteo for trying out our activities at home before they went public.

\section{Funding}

Funding for this project came from Sydney Social Sciences and Humanities Advanced Research Centre (SSSHARC) 'Human Perspectives on the Nano Scale, Sydney Nano Pilot Program' (2018) and Sydney Nano (2018).

\section{References}

Al-Khayat, O., Hong, J., Beck, D., Minett, A., \& Neto, C. (2017). Patterned polymer coatings increase the efficiency of dew harvesting. ACS Applied Materials and Interfaces, 9(15), 13676-13684.

Alpers, S. (1983). The art of describing. Dutch art in the seventeenth century, London: Penguin Books.

Arasse, Daniel. (2013). Take a closer look. Translated by Alyson Waters. Princeton University Press

Butler, R. (1987). The prints of Margaret Preston: A catalogue raisonné. Canberra: Australian National Gallery; Melbourne Oxford University Press.

CONASTA 67. 2018 national conference of the Australian Science Teachers Association, Accessed 17th June 2019 from: https://asta.eventsair.com/QuickEventWebsitePortal/conasta-67/event-home-page

Carbon, C.-C. (2017). Art perception in the museum: How we spend time and space in art Exhibitions. IPerception, 8(1), 1-14. https://doi.org/10.1177/2041669517694184

Edwards, D., Preston, M., Peel, R., \& Mimmocchi, D. (2005). Margaret Preston. Sydney: Art Gallery of New South Wales.

Greenblatt, S. (1990). 'Resonance and wonder'. In B. M. Carbonell (Ed.), Museum studies: An anthology of contexts (pp. 541-555). Oxford: Blackwell.

Jay, M. (1994). Downcast eyes. The denigration of vision in twentieth-century French thought. Berkley: University of California Press.

Katselas, A., Motion, A., O’Reilly, C., \& Neto,C. (2019). Chemical curiosity on campus: An undergraduate project on the structure and wettability of natural surfaces. J. Chem. Ed. Accepted.

Kelly, M. (2018). Madeleine Kelly. Retrieved 2 March 2019, from https://www.madeleinekelly.com.au/

Lawrenson, A. \& O'Reilly, C. (2018). The rise of the must-see exhibition. Blockbusters in Australian museums and galleries. London: Routledge.

Locher, P. J. (2015). The aesthetic experience with visual art “At First Glance”. In P. F. Bundgaard \& F. Stjernfelt (Eds.), Investigations into the phenomenology and the ontology of the work of art: What are artworks and how do we experience them? (pp. 75-88). Cham: Springer International Publishing. https://doi.org/10.1007/978-3-319-14090-2_5

Motion, A., Neto C., \& O'Reilly C. (2019). Looking through the nano lens. Muse: Art culture. antiquities. natural history. University of Sydney museums. 16-17.

O'Reilly, C. (2019), Collecting French art in the late 1800s at the Art Gallery of New South Wales. Journal of the History of Collections fhz006, https://doi.org/10.1093/jhc/fhz006

Preston, M. (1929). 92 Aphorisms by Margaret Preston and others. In S. Ure Smith \& L. Gellert (Eds.), Margaret Preston: Recent paintings, 1929. Sydney: Art in Australia.

Scarratt, L., Steiner, U., \& Neto, C. (2017). A review on the mechanical and thermodynamic robustness of superhydrophobic surfaces. Advances in Colloid and Interface Science, 246, 133-152

Scarratt, L., Zhu, L., \& Neto, C. (2019). How slippery are SLIPS? Measuring effective slip on lubricated surfaces with colloidal probe atomic force microscopy. Langmuir, 35(8), 2976-2982. 
Smith, L. F., Smith, J. K., \& Tinio, P. P. L. (2017). Time spent viewing art and reading labels. Psychology of Aesthetics, Creativity, and the Arts, 11(1), 77-85. https://doi.org/10.1037/aca0000049

Tishman, S. (2018). Slow looking: The art and practice of learning through observation. New York, NY ; Abingdon, Oxon: Routledge.

Trends in public attitudes to science | NCCPE. (2018). Accessed 17th June 2019, from https://www.publicengagement.ac.uk/nccpe-projects-and-services/nccpe-projects/national-forum-publicengagement-stem/trends-public-attitudes-science

Ure Smith, S. (1945, June 3). Australian artists speak: Margaret Preston, interviewed by Sydney Ure Smith [Typescript of a radio broadcast interview for 2FC Radio].Copy held in the Research Library and Archive, Art Gallery of New South Wales.

Ware, C., Smith-Palmer, T., Peppou-Chapman, S., Scarratt, L., Humphries, E., Balzer, D., \& Neto, C. (2018). Marine antifouling behavior of lubricant-infused nanowrinkled polymeric surfaces. ACS Applied Materials and Interfaces, 10(4), 4173-4182.

Williamson, A.E., Ylioya, P. M., Robertson, M. N., et al (2016) Open source drug discovery: Highly potent antimalarial compounds derived from the Tres Cantos Arylpyrroles, ACS Cent. Sci., 2016, 2, 687-701. 